\title{
(University) Management after Valuation Studies: Carving a practice between the offended native, the anxious scholar, and the useless practitioner
}

\author{
José Ossandón
}

\begin{abstract}
This text introduces this issues' symposium: "A correspondence on (University) Management after Valuation Studies". The text has two parts. The first introduces the dilemma, the question of whether valuation studies could, besides studying valuation in practice, inform better practices of valuation, and the method of the correspondence, to use situations in which researchers of valuation are also practitioners, namely, the management of quality in higher education, as the starting point to think the correspondence's problem. In the second part, the author reflects on his own experience in a situation of valuation at work, and proposes three different personae for the student of valuation: the offended native, the anxious scholar, and the useless practitioner.
\end{abstract}

Keywords: valuation; rankings; higher education; management; judgment

José Ossandón is an Associate Professor at the Department of Organization, Copenhagen Business School

\author{
(c) 2021 The authors (cc)BY \\ Attribution 4.0 International License. \\ https://doi.org/10.3384/VS.2001-5992.2021.8.61-72 \\ Hosted by Linköping University Electronic press \\ http://valuationstudies.liu.se
} This work is licensed under a Creative Commons 
Valuation studies is a productive academic movement developed after scholars in areas such as sociology (e.g. Antal et al. 2015, Beckert and Aspers 2011, Beckert and Musselin 2013); organization theory and strategy (e.g. Kornberger 2017, Kornberger et al. 2015); and science and technology studies (e.g. Dussauge et al. 2015) realized that there was plenty to learn from valuation situations and practices. This correspondence reflects upon whether or not this exchange may be reciprocal. Can practitioners - those involved in the everyday work of running organizations that are affected by new and powerful forms of valuation - learn from valuation studies? To think through this problem, participants in this correspondence discuss whether recent studies of valuation can help those involved in the practice of managing a type of organization in which we are also practitioners: does the knowledge produced in valuation studies have something to say to those involved in managing universities?

$* * *$

What recent studies of valuation have done is to make valuing, and valuation tools and practices, objects of social scientific inquiry. ${ }^{1}$ Most contributions in the area have been either descriptive and critical research that on the basis of ethnographic work inspects the inner logic or vernaculars of 'valuation devices' (Muniesa and Doganova 2020) or explicative - research that aims at uncovering mechanisms for instance, reactivity (Espeland and Sauder 2007) - that explain how valuation devices affect the practices of those who interact with them. Studies of valuation have been written and produced from the perspective of the scholar who inspects new objects of inquiry. The point of this conversation is to explore the possible gains of shifting the angle and using valuation studies to deal with the problems of valuation in practice.

Of course, the point is not to confuse the positions of the scholar and the practitioner. The researcher's perspective is naturally more abstract and detached, and it is up to actual practitioners to figure out whether they can productively use whatever is produced in recent academic research. ${ }^{2}$ There is also no point in denying the obvious,

1 Of course, there is a much larger history of academic interest in valuation and valuing in other specialized academic areas, for instance, financial accounting (Mennicken and Sjögren 2015) and pedagogy. The particularity of valuation studies is making these processes problems of social science inquiry more broadly.

2 As James March put it: "If a manager asks an academic consultant what to do and that consultant answers, then the consultant should be fired. No academic has the experience to know the context of a managerial problem well enough to give specific advice about a specific situation" (in Coutu [2006]). 
most academic developments are only academically relevant. They are important as they create new objects and methods of research but not -necessarily - new ways of practicing. However, it is worth asking whether - after ten or more years and besides equipping us, academic researchers, with productive new concepts and methods to do our work - studies of valuation can help in some way to make the situation of contemporary organizations and practitioners better. Does the knowledge produced in valuation studies have something to say to those involved in the management of organizations?

How to speak to practitioners after valuation studies? Studies of valuation impose difficult constraints! If studies of valuation have shown something, it is that researchers should respect the craft and art of valuing. Issues regarding valuing cannot be solved in general theoretical terms. To speak about the practice of management after valuation studies, accordingly, we had to devise a trick. The inspiration for the format comes from a debate Christine Musselin and Catherine Paradeise (2005) published in Sociologies du Travail. This special section, likewise, does not collect papers, it hosts a dialogue. We call it a "correspondence", like in an epistolary exchange. A difference, though, is that participants in this section were not invited to present and contrast their theories about a common issue. It is a different type of conversation. With the inspiration of similar exercises in science and technology studies, we started from the specific experience of the contributors in an area in which we are all practitioners. ${ }^{3}$ Like a selftherapeutic experiment, rather than beginning by giving advice to others of how they could use insights coming from studies of valuation, we ask can we use what the field has taught us for ourselves?

It is in universities where we conduct valuations, we are valued, and we manage valuation practices. To think about the possible impact of studies of valuation in management, the contributions in this correspondence discuss whether recent studies of valuation can help, not only to better explain the current situation that characterizes the valuation ecology of universities, but also to provide relevant insights to those involved in the practice of managing universities.

\footnotetext{
${ }^{3}$ See for instance the pieces included in the special issue "Unpacking 'Intervention' in Science and Technology Studies" Zuiderent-Jerak and Bruun Jensen (2007) edited in Science as Culture; and, even closer, the thematic collection "Implicated in the Indicator Game? An Experimental Debate" Fochler and de Rijcke edited in Engaging Science, Technology, and Society (e.g. Fochler and de Rijcke 2017). In terms of the format, another source of inspiration is the journal Sociologica, which has made its speciality the art of developing productive debates. See, among many examples, the symposium on academic publications that in fact also features contributions by Espeland (2019), Kreiner (2019), and Musselin (2019). For another and related example use of provocation pieces to trigger an academic-professional debate see Woolgar et al (2009).
} 


\section{Valuation Studies}

Four contributions make this correspondence. The first is this introduction including the short note that follows, in which I use my experience with a very mundane task of research organization, the elaboration of a new publication list in the department where I work, as a provocation to initiate a debate on valuation studies and valuation in practice. In her response, Christine Musselin uses concepts from recent studies to inspect her own experience assessing researchers. In the third text, Kristian Kreiner uses the publication strategy I discuss, which is also about the department where Kreiner is an emeritus professor, to critically reflect on the expectations and functions of rankings in the management of quality in research institutions. The fourth and final text is a conversation with Wendy Espeland and Michael Sauder, where they discuss and reflect the possible uses of their very influential work on the sociology of rankings in managing universities.

\section{The anxious scholar, the useless practitioner, and the offended native}

What follows is a note sharing my reflections after an experience with a mundane situation of quality management at work. This note, it should be said, should not be read as an ethnographic inquiry or a fully developed case study. This would require that I both knew much more than I know about the particularities of the Danish institutional framework and its history, and that I had developed a method of research for the occasion. I share this note, nevertheless, because it has a different purpose. It is to present the thoughts which the situation I describe triggered about the roles or personae valuation scholars might play in practice, which, in turn, worked as a provocation to initiate the dialogue in this symposium.

$* * *$

As is normally the case with this type of situation, this story began when I raised my hand at the wrong meeting.

The meeting was to discuss a new publication strategy for the department where I work. The instruction that we needed a new strategy was a requirement of the boss of our boss, the dean of research. The instruction was that each department should deliver an updated publication strategy. The strategy should include: the department's view on publication quality and the outlets to which they expect to give priority; the department's publication patterns over the past five years; the goals for publications for the next five years; and a plan for activities to follow up the implementation of the strategy. During the meeting it was decided that a task force would be formed and that the force would be in charge of collecting the views posed in plenary and preparing a document to be submitted to the dean. Five 
researchers, three associate professors (including me), and two full professors volunteered. The head of department also joined and formally led the task force.

Here some contextual information might help. Copenhagen Business School (CBS) is a large school with departments with very different styles of research. The term used locally is of 'business university' in order to stress that the institution does not only host research and education in traditional business areas (e.g. accounting, marketing, finance), but also in social sciences and humanities (such as business history and philosophy, economic sociology, or critical management studies). Deans of research have dealt with this multiplicity in different ways. Some, in the past, tried to engage with the different styles of reasoning and attempted to understand how different departments do research. Others assumed that it was not up to them to assess the different areas and gave departments more autonomy. The current dean seems to take a third stance. The following quotation from an interview he gave to the university's online news outlet express this positional neatly:

The h-index isn't an important indicator to me [...] As a dean, I'm more interested in a candidate's best work. In economics, for instance, there are only five top journals, and if you manage to get a scientific paper in one of those, it indicates that the research is of truly high quality [...] In that sense, we do count the number of articles, but only the really good ones. And we certainly also look at impact when we consider hiring a researcher. Having impact outside academia is clearly important for a business school. ${ }^{4}$

High quality seems to mean to this dean research published in highly ranked journals. The dean likes competitive goals and expects researchers (and departments) to set high targets for themselves. But it is for each department to define their own highly ranked journals. Locally, at least for the work developing this strategy, this was translated into a rule of thumb (I don't know if it is actually what the dean thinks, but it is how he seems to be interpreted at least): senior management will recognize as high quality, publications that appear in outlets that have a high position (at least in tier 3, but preferably in tiers 4 or $4 *$ in the so-called "ABS List".

Of course, and as in many other countries (e.g. Musselin 2018), this state of affairs does not only respond to the different deans' various styles of reasoning. This responds also to changes in the institutional environment; particularly how the governance of Danish universities is increasingly "performance-based". Publication targets like the list discussed here respond to the development contract between Danish universities and the Ministry of Higher Education and

4 https://cbswire.dk/dean-of-research-unread-research-is-not-a-waste/ (last accessed December 9,2021). 
Science. An important instrument in this context is the "Danish Bibliometric Research Indicator”. As an official guideline explains:

The Bibliometric Research Indicator (BFI) is an element of the performancebased model for distribution of new block grants for research to universities. The BFI is used to allocate funding based on the production of research publications that are peer-reviewed and published in a channel included on the BFI lists. It is based on the universities' registration of publications in the Pure current research information system (CRIS). Publications are counted once a year and, subsequently, awarded points in the BFI system ${ }^{5}$

At CBS, the BFI list coexists with the "ABS List", the performance instrument produced and maintained by the Chartered Association of Business in the UK. Colleagues that have more experience in higher instances of CBS's decision making say that the fact that, in CBS the ABS list is actually more powerful than the Danish official BFI list, responds at least partially to pressure from sectors of the local academic population that consider this list more relevant.

The discussion in the task force was not simple, as it tended to involve many layers. One discussion was about the number of items to include in the list. The head of department suggested that, unlike a previous attempt to construct a publication guide in our department, we should avoid making a too large list of outlets. (There was a previous list which had 50 journals and did not consider metrics or rankings, and included those publications which researchers in the department had found relevant in the past). In the end, the task force assumed that the main task was to select a list of 15 journals and that these journals should be highly ranked, either on the ABS list or in other relevant rankings. The task force also agreed that the list should include two types of publications. Some 'generalist' journals that are relevant to most in the Department of Organization (the list ended up including outlets like Organization Studies, Organization and Organization Science) while others had to be more specific, journals relevant to some of the main areas of research currently conducted in the department (for instance, political economy or public governance). In order to collect information on those journals that people at the

5 https://ufm.dk/forskning-og-innovation/statistik-og-analyser/den-bibliometriske$\underline{f}$ o r s k n i n g s i n d i k a t o r / B F I s - r e g l e r / guidelines for registering research for the danish bibliometric research indicator. pdf (last accessed November 22, 2021). 
department considered important, the task force prepared and distributed an internal informal survey. ${ }^{6}$

Another discussion was about the type of outlets, particularly, how to accommodate books. In the end, it was agreed to state as a principle that books - and not only journal articles - are to be seen as relevant in the department strategy. The final document stated:

[W]e aim to publish books with renowned international publishing houses in addition to publishing in leading international journals [and] [w]e emphasize two ambitions: - Books and edited volumes with distinguished publishing houses will comprise a notable share of the department's publications. - We aim that our rate of publication within the IOA15-list will accelerate from the 2018 baseline. ${ }^{7}$

Yet a different layer regarded the potential uses of the strategy. Will this document only be used in the interaction between the dean and the head of department? Will these set collective assessment criteria - those expected of the department as a whole - be used to assess individuals? Will the strategy affect salaries, bonuses, and hiring decisions? In the end, the task force decided to add some guidance on how the list is expected to be used. For example, the document says: "The list is not meant to exclude, but to guide and inspire faculty, as well as inform stakeholders interested in the composite research profile of the department". Finally, a great deal of time was used in discussing how to carefully phrase the document, for instance, how to make measurable goals seem both ambitious and practically realistic.

While I participated in this process, I experienced ambivalent sensations. The situation provoked reactions in the different personae that I normally enact but that normally I try to keep separate. I call them the native, the scholar, and the practitioner.

The first reaction was that of an offended native. This reaction was not so different from other professionals who feel that external valuation mechanisms are ignorant in relation to the values of what they really do. It is a bit like the musicians Howard Becker (1951) studied many years ago who were offended by those who assessed their work without understanding the details of their craft. In my case, I felt that the ABS list did not represent quality: lists like this are instruments made for those who cannot understand what good

${ }^{6}$ The final list included: Academy of Management Journal, Academy of Management Review, Accounting, Organizations and Society, Human Relations, Journal of Management Studies, New Political Economy, Organization, Organization Science, Organization Studies, Public Administration: An International Quarterly, Public Management Review, Research Policy, Review of International Political Economy, Socio-Economic Review, and Sociological Review.

7 This and the following quotations come from the official document, "IOA Publication Strategy", available in the local intranet: https://cbsshare.cbs.dk/teams/ afdelinger/ioa/Politikker/Forms/AllItems. aspx (last accessed November 23, 2021). 


\section{Valuation Studies}

research is, for instance professional managers that might need a number to assess their work or to help librarians to select journal subscriptions, ${ }^{8}$ and it does not make sense as an instrument to use among academics. It was frustrating to see that the university where I work is spending a great deal of energy and time thinking about something that is at the core of what we do - to produce better quality research - in the wrong way. The exercise had nothing to do with thinking how we can better organize ourselves - as organization and department - so we do research that is actually better. The exercise assumed that the production of quality is a black box and that the energy should be oriented to set the right targets and incentives. The exercise, I felt, would in no way produce a department that is better equipped to produce more interesting or original research. And, at the same time it might produce the sensation, to the deanery for instance, that we are actually confronting the key problem, but without really doing much about it.

The second sensation was of an anxious valuation scholar. During the whole process I felt, largely thanks to the previous work of the contributors to this correspondence and by others, that I had the tools to understand the process in which I took part. I knew that a key issue today is that universities - like other professional organizations are increasingly pushed to compete among themselves. Universities and the different actors that inhabit them (deans, departments, faculties, students) are managed through competition (Musselin 2018). Of course, competitive struggles have existed for longer, but what is relatively new is university governance that uses competition as an instrument of management, and that - especially in the European university system - competition is not about prices or attracting customers, it is about quality (Musellin 2018). We are in an economy of quality, and academic quality - as in many other areas, for example, cuisine, architecture, or art - is often contested and difficult to assess. The pressure for competition has become a fertile soil for the proliferation of "judgment devices" (Karpik 2010), tools like rankings, lists, internet forums, etc., that help the different actors involved in the university field (funders, managers, prospective students, researchers) to assess and manage academic quality. These devices, in turn, have greatly transformed the whole field. Today, increasingly, managers at different levels (deans, heads of departments, those in charge of admission) are assessed in terms of their institution's relative position on different lists. Deans are not simply researchers that double as administrators (Espeland and Sauder 2016). Deans are increasingly professional managers that govern by producing internal competition,

\footnotetext{
${ }^{8}$ For instance, as explained in the San Francisco Declaration on Research Assessment (DORA), "The Journal Impact Factor, as calculated by Thomson Reuters", was originally created as a tool to help librarians identify journals to purchase, not as a measure of the scientific quality of research in an article" https://sfdora.org/read/
} 
and accordingly orienting incentives - like bonuses and promotions directly to goals such as improving the institution's relative position in rankings (Musselin 2018). In this context, universities work more and more on competitive strategies and on producing statistics to assess their success.

This sensation was not emotionally neutral. It was, maybe because at the same time I was reading Engines of Anxiety (Espeland and Sauder 2016), anxious. What recent research shows is not only a transformed landscape, but also a scary picture. Therefore, while I was doing all this, I kept thinking what if we were not going through one strategy exercise among many without practical consequences? We do that all the time anyway, but what if this time, we were about to finally turn into the dystopian world our colleagues in the UK often describe? What if this strategy changes how the department is assessed in the future? Could this affect the current perception that we work in a department that is internationally recognized as good and original, and change it into a department that is seen as failed because it cannot publish in the journals set as targets? Shouldn't we listen to the message that when rankings become targets they turn into dangerous devices? Are we not only setting goals that are out of our hands (that papers are or not published depends on many external factors) but also - as most of us will try to publish in a more focused list of places - actually reducing the chance of the strategy's success? Can we trust our top managers to keep on having a reflexive and more or less cynical attitude in relation to publication metrics in the future?

The last sensation was that of a useless practitioner. In the end, I became very disappointed with my participation in the whole affair. I spent a great deal of energy trying to put all these issues on the table, but, somehow, nothing I said was very controversial. Whatever I said could not really change how to think about the situation. This is not, I cannot stress this enough, to blame my colleagues in the task force. I know they acted pragmatically and carefully. It is to blame me. I realized that valuation studies provided me with good concepts to describe a situation like the one I encountered, but that it did not necessarily help me to produce tools that could manage the problem differently. I became the complaining anxious valuation scholar in the room. I felt that I had much to say and many concepts to describe what was going on, but that these did not translate into insights of how to act better. In the end, the only thing I did was to help writing warning sentences - (for instance, the strategy stated:

For us, even though they are important, leading journals cannot always be reduced to a matter of ranking as innovative contributions are often also published in new journals or sector specific journals that encourage new avenues of thinking and exploring.) 
But the overall sensation is that I didn't really provide any insight on how to manage this situation in a way that, instead of adding well intended sentences that would be like footnotes which, while cleaning my conscience, would simply be forgotten as the list is used, could help in thinking about a policy that could avoid journal lists and performance based tools as the instrument of our department research strategy.

It is primarily this troubled sensation of uselessness that motivated me to initiate this correspondence. Can the concepts and findings of valuation studies become useful in organizing and managing academic research quality better? To think through this difficult problem, I decided to turn to those with much more knowledge and experience. Not only those who know a lot about valuation from a scholarly perspective, but also those with much more practical experience in the organization and management of universities.

\section{References}

Antal, Ariane Berthoin, Michael Hutter, and David Stark (Eds.). 2015. Moments of Valuation: Exploring Sites of Dissonance. Oxford: Oxford University Press.

Becker, Howard S. 1951. "The Professional Dance Musician and His Audience." American Journal of Sociology 57(2): 136-144.

Beckert, Jens, and Patrik Aspers (Eds.). 2011. The Worth of Goods: Valuation and Pricing in the Economy. Oxford: Oxford University Press.

Beckert, Jens, and Christine Musselin (Eds.). 2013. Constructing Quality: The Classification of Goods in Markets. Oxford: Oxford University Press.

Coutu, Diane. 2006. “Ideas as art.' The HBR interview with James G. March." Harvard Business Review 84(10): 82-89.

Dussauge, Isabelle, Claes-Fredrik Helgesson, and Francis Lee (Eds.). 2015. Value Practices in the Life Sciences and Medicine. Oxford: Oxford University Press.

Espeland, Wendy. N. 2019. “What's Good Enough?” Sociologica 13(1): 1316.

Espeland, Wendy. N., and Michael Sauder. 2007. "Rankings and Reactivity: How Public Measures Recreate Social Worlds.” American Journal of Sociology 113(1): 1-40.

Espeland, Wendy. N., and Michael Sauder. 2016. Engines of Anxiety: Academic Rankings, Reputation, and Accountability. Russell Sage Foundation.

Fochler, Maximilian, and Sarah De Rijcke. 2017. "Implicated in the Indicator Game? An Experimental Debate." Engaging Science, Technology, and Society 3: 21-40.

Karpik, Lucien. 2010. The Economics of Singularities. Princeton, NJ: Princeton University Press. 
Kornberger, Martin. 2017. "The Values of Strategy: Valuation Practices, Rivalry and Strategic Agency." Organization Studies 38(12): 1753-1773.

Kornberger, Martin, Lise Justesen, Anders Koed Madsen, and Jan Mouritsen (Eds.). 2015. Making Things Valuable. New York: Oxford University Press.

Kreiner, Kristian. 2019. “On Publication Strategies.” Sociologica 13(1): 29_ 31.

Mennicken, Andrea, and Ebba Sjögren. 2015. "Valuation and Calculation at the Margins.” Valuation Studies, 3(1): 1-7.

Muniesa, Fabian, and Liliana Doganova. 2020. “The Time That Money Requires: Use of the Future and Critique of the Present in Financial Valuation." Finance and Society 6(2): 95-113.

Musselin, Christine. 2018. "New Forms Of Competition In Higher Education." Socio-Economic Review 16(3): 657-683.

Musselin, Christine. 2019. "A Balanced Publication Strategy." Sociologica 13(1): 45-50.

Musselin, Christine, and Catherine Paradeise. 2005. "Quality: a debate." Sociologie du travail, 47(Supplément 1): 89-123.

Woolgar, Steve, Catelijne Coopmans, and Daniel Neyland.. 2009. "Does STS mean business?." Organization, 16(1): 5-30.

Zuiderent-Jerak, Teun, and Casper Bruun Jensen. 2007. "Editorial Introduction: Unpacking 'Intervention' in Science and Technology Studies. Science as Culture 16(3): 227-235.

José Ossandón is Associate Professor in the Organization of Markets, Department of Organization, Copenhagen Business School. He specializes in economic sociology, social studies of finance, and social studies of markets. His current collaborative research efforts focus on two main areas, the work and techniques deployed in the organization of markets designed to deal with collective problems, and, on the different actors and practices involved in managing households' finance. He is co-editor-in-chief of Valuation Studies and senior editor of The Journal of Cultural Economy. 
